\title{
MODEL ANALISIS KEPUASAN DAN LOYALITAS WISATAWAN LOKAL STUDI KASUS PADA OBJEK WISATA KEPULAUAN SERIBU JAKARTA
}

\author{
Rosa Lesmana ${ }^{1),}$ Wiwik Hasbiyah ${ }^{2)}$ \\ 1) dosen universitas pamulang, email : dosen01360@unpam.ac.id \\ ${ }^{2)}$ dosen universitas pamulang, email : wiwik.hasbiyah@yahoo.com
}

\section{ARTICLES \\ INFORMATION}

ABSTRACT

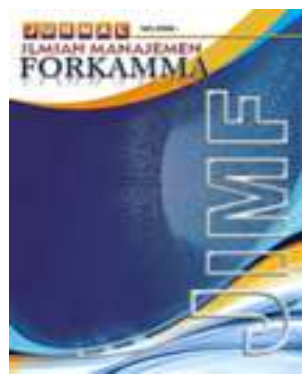

\section{JURNAL ILMIAH MANAJEMEN FORKAMMA}

Vol.2, No.3, Juli 2019

Halaman : $36-47$

(c) LPPM \& FORKAMMA

Prodi Magister Manajemen

UNVERSITAS PAMULANG

ISSN (online) : 2599-171X

ISSN (print) : :2598-9545

\section{Keyword :}

Satisfaction and Loyalty

JEL. classification :

C33, G20, G23, N65

\section{Contact Author :}

PRODI
MAGISTER MANAJEMEN \&
FORKAMMA UNPAM
JL.Surya Kencana No.1 Pamulang
Tangerang Selatan - Banten
Telp. (021) 7412566, Fax (021) 7412491
Email:
uurnalforkamma.unpam@gmail.com

Tujuan penelitian ini untuk mengetahui pengaruh kepuasan wisatawan terhadap loyalitas wisatawan, untuk mengetahui pengaruh kepuasan tujuan umum (general destination satisfaction), tingkat kepuasan rata-rata dalam hal atribut tujuan (attribute satisfaction) dan sejauh mana harapan terpenuhi (met expectation) terhadap kepuasan wisatawan dan untuk mengetahui intention to return dan kemauan untuk merekomendasikan (willingness to recommended) terhadap loyalitas. Sampel terdiri dari 150 wisatawan Kepulauan Seribu. Pengolahan data menggunakan AMOS 23. Hasil penelitian didapat kepuasan wisatawan berpengaruh positif terhadap loyalitas wisatawan lokal pada objek wisata Kepulauan Seribu Jakarta, kepuasaan tujuan umum (general destination satisfaction), kepuasan atribut tujuan (attribute satisfaction) dan kepuasaan harapan (met expectation) berpengaruh positif terhadap kepuasan wisatawan lokal pada objek wisata Kepulauan Seribu Jakarta dan Niat untuk kembali (intention to return) dan kemauan untuk merekomendasikan (willingness to recommended) berpengaruh positif terhadap loyalitas.

This study aims to determine the effect of tourist satisfaction on tourist loyalty, to determine the effect of general purpose satisfaction (general destination satisfaction), the average level of satisfaction in terms of destination attributes (attribute satisfaction) and the extent to which expectations are met (met expectation) to tourist satisfaction and to know intention to return and willingness to recommend loyalty. The sample of this study are 150 Kepulauan Seribu tourists. AMOS 23 is used to analyze the data. The analysis shows that tourist satisfaction has a positive effect on the loyalty of local tourists in Kepulauan Seribu Jakarta. General destination satisfaction, attribute satisfaction, and met expectation have a positive effect on local tourist satisfaction on the Kepulauan Seribu Jakarta Thousand . Intention to return and willingness to recommend) has a positive effect on loyalty. 


\section{A. Pendahuluan}

\section{Latar Belakang Masalah.}

Di masa kini, pariwisata adalah bidang yang memiliki peranan yang sangat menunjang dalam pembangunan ekonomi. Sektor pariwisata merupakan salah satu sumber penghasil devisa yang sangat baik. Salah satunya Kepulauan Seribu Jakarta. Berikut merupakan data kunjungan wisatawan Kepulauan Seribu, Jakarta beberapa tahun terakhir:

Tabel 1 Kunjungan Wisatawan Kepulauan Seribu Tahun 2013-2017

\begin{tabular}{|c|c|c|}
\hline \multirow{2}{*}{ Tahun } & \multicolumn{2}{|c|}{ Jumlah Wisatawan } \\
\cline { 2 - 3 } & Nusantara & Mancanegara \\
\hline 2013 & 1.138 .900 & 16.384 \\
\hline 2014 & 1.773 .026 & 12.254. \\
\hline 2015 & 853.213 & 10.996 \\
\hline 2016 & 810.027 & 24.517 \\
\hline 2017 & 850.240 & 28.731 \\
\hline
\end{tabular}

Sumber : Dinas Kebudayaan dan Pariwisata DKI Jakarta, 2017

Penelitian yang akan dilakukan akan memodifikasi penelitian Valle, Silva, Mendes, Guerreiro (2006) dengan menggunakan variabel kepuasaan wisatawan menggunakan model karakteristik (sosio-demografis dan motivasional) yang lebih berpotensi kepuasaan wisatawan serta dengan menggunakan variabel loyalitas wisatawan yang akan membentuk niat kembali berkunjung (intention to return) di industri pariwisata Kepulauan Seribu. Berdasarkan uraian di atas maka penulis tertarik untuk melakukan penelitian dengan judul "Model Analisis Kepuasaan dan Loyalitas Wisatawan Lokal Studi Kasus pada objek wisata Kepulauan Seribu, Jakarta"

\section{Perumusan Masalah}

1) Apakah kepuasaan wisatawan mempunyai pengaruh terhadap loyalitas wisatawan ?

2) Apakah kepuasan tujuan umum (general destination satisfaction), tingkat kepuasan rata-rata dalam hal atribut tujuan (attribute satisfaction) dan sejauh mana harapan terpenuhi (met expectation) mempunyai pengaruh terhadap kepuasan wisatawan?

3) Apakah minat kembali (intention to return) dan kemauan untuk merekomendasikan (willingness to recommended) mempunyai pengaruh terhadap loyalitas?

\section{Tujuan Penelitian}

1) Untuk mengetahui pengaruh kepuasaan wisatawan terhadap loyalitas wisatawan

2) Untuk mengetahui pengaruh kepuasan tujuan umum (general destination satisfaction)", tingkat kepuasan rata-rata dalam hal atribut tujuan (attribute satisfaction)" dan "sejauh mana harapan terpenuhi (met expectation)" terhadap kepuasan wisatawan.

3) Untuk mengetahui intention to return dan kemauan untuk merekomendasikan (willingness to recommended) terhadap loyalitas 


\section{B. Kajian Teori}

\section{Kepuasan Wisatawan}

Kepuasan pelanggan, atau kepuasan wisatawan mengacu pada hasil evaluasi wisatawan dan perbandingan persepsi kinerja produk atau layanan dengan harapan (Heung dan Cheng, 2000). Jika kinerja melebihi harapan, hasilnya adalah kepuasan wisatawan, namun, ketika ekspektasi melebihi kinerja, hasilnya adalah ketidakpuasan. Kepuasan turis penting dalam pemasaran destinasi karena memengaruhi pilihan destinasi, konsumsi barang dan jasa, jumlah kunjungan

berulang, publisitas dari mulut ke mulut, dan loyalitas tujuan (Kozak dan Rimmington, 2000; Kozak, Bigne, dan Andreu, 2004). Kepuasan wisatawan dapat ditentukan oleh perbandingan wisatawan tentang harapan mereka terhadap suatu destinasi dan pengalaman evaluatif yang dirasakan di tempat tujuan (Yoon dan Uysal, 2005) dalam jurnal (Sangpikul, 2018). Pemahaman tentang kepuasan wisatawan adalah alat dasar untuk mengevaluasi kinerja produk dan layanan tujuan (Schofield, 2000 dikutip dalam Yoon dan Uysal, 2005). Oleh karena itu, pemantauan kepuasan wisatawan merupakan tugas penting bagi otoritas/perencana tujuan untuk mendapatkan umpan balik dan mendeteksi masalah yang menyebabkan ketidakpuasan wisatawan yang mungkin berdampak negatif pada kunjungan di masa mendatang (Reisinger dan Turner, 2003). Oleh karena itu, penilaian kepuasan wisatawan sehubungan dengan destinasi pulau dapat membantu manajer destinasi menyesuaikan upaya mereka untuk meningkatkan pengalaman perjalanan wisatawan dan mengembangkan strategi pemasaran destinasi yang efektif (Kozak dan Rimmington, 2000; Yoon dan Uysal, 2005).

\section{Loyalitas Wisayatawan.}

Konsep loyalitas merupakan salah satu indicator yang penting dari kesuksesan perusahaan (La Barbara dan Mazursky, 1983; Turnbull dan Wilson, 1989; Pineet, 1995; Bauer et al., 2002). Menurut Hallowell (1996) ada hubungan antara loyalitas dan profitabilitas, karena pelanggan setia akan mengurangi biaya perekrutan pelanggan, sensitivitas harga pelanggan dan biaya servis. Dalam hal pemasaran produk dan layanan tradisional, loyalitas dapat diukur dengan penjualan berulang atau oleh rekomendasi kepada konsumen lain (Pine et al., 1995). Menurut Yoon dan Uysal (2005) menekankan bahwa tujuan wisata juga dapat dijadikan sebagai produk yang dapat dijual kembali dan direkomendasikan kepada orang lain (teman dan keluarga yang merupakan wisatawan potensial). Loyalitas wisatawan adalah salah satu aspek paling penting tujuan bagi pemasar karena lebih diinginkan, dan lebih murah, untuk mempertahankan wisatawan yang sudah ada daripada menarik wisatawan baru (Loureiro dan González, 2008). Wisatawan dengan tingkat loyalitas yang tinggi mewakili segmen pasar yang penting untuk banyak tujuan wisata, karena mereka lebih cenderung tinggal lebih lama di destinasi daripada pengunjung pertama kali. Loyalitas wisatawan cenderung menyebarkan informasi positif melalui mulut ke mulut (WOM) dan berpartisipasi dalam kegiatan konsumtif lebih intensif (Li et al., 2010; Zhang et al.,2014).

\section{Kerangka Berpikir.}

Penelitian ini akan mengacu kepada penelitian yang telah dilakukan sebelumnya oleh Valle, Silva, Mendes, Guerreiro (2006). Penelitian yang akan dilakukan akan memodifikasi penelitian Valle, Silva, Mendes, Guerreiro (2006). 
Model Penelitian yang digunakan diadopsi dari Valle, Silva, Mendes, Guerreiro (2006)

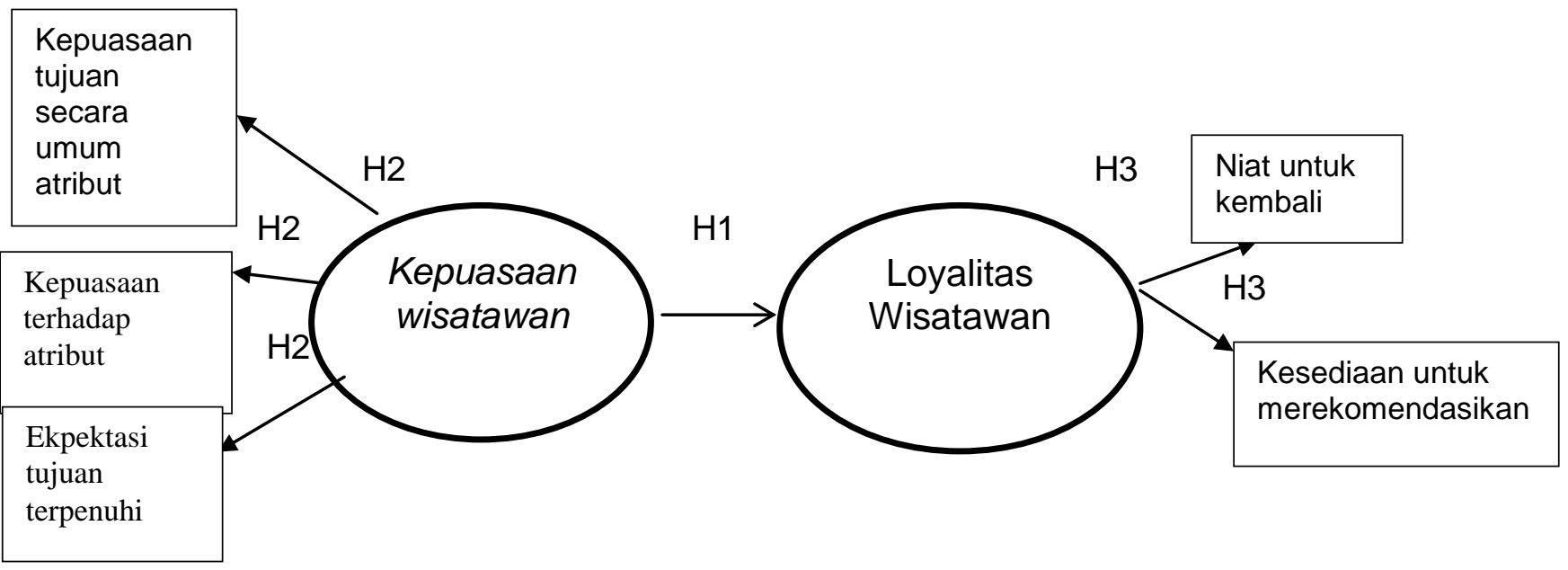

\section{Gambar 1. Kerangka Berpikir}

\section{Metodologi Penelitian}

1. Obyek Penelitian.

Pengunjung Objek Wisata Kepulauan Seribu Jakartaya

\section{Populasi dan Sampel.}

a. Populasi

Populasi adalah wilayah generalisasi yang terdiri atas : objek/subjek yang mempunyai kuantitas dan karakteristik tertentu yang ditetapkan oleh peneliti untuk dipelajari dan kemudian ditarik kesimpulannya.(Sugiono, 2013). Dalam penelitian ini populasi adalah pengunjung atau wisatawan kepulauan seribu, Jakarta.

b. Sampel

Peneliti memilih responden sebanyak 150 orang berdasarkan pengetahuan dan pandangan peneliti yang menilai bahwa seorang yang menjadi anggota populasi tersebut layak untuk menjadi sampel dalam penelitian ini.

\section{Metode Analisis Data.}

Metode yang digunakan dalam penelitian ini adalah metode kuantitatif yang merupakan metode penekitian yang berlandaskan pada filsafat positivisme, digunakan untuk meneliti pada populasi atau sampel tertentu, pengumpulan data menggunakan instrumen penelitian, analisis data bersifat kuantutatif/statistik, dengan tujuan untuk menguji hipotesis yang telah ditetapkan. (Sugiono, 2013). Data dianalisi dengan menggunakan Amos 
Operasionalisasi variabel merupakan hal yang penting untuk memperoleh data yang dapat menguji hipotesis dan melihat kecocokan model yang telah dibangun berdasarkankonstruk teori.

\section{Hasil Analisis Data}

1. Uji Instrumen Penelitian

a. Uji Validitas Data

Tabel 2 Hasil Uji Validitas Kepuasaan Wisatawan

\begin{tabular}{|c|c|c|c|c|c|c|}
\hline \multicolumn{2}{|c|}{ Variabel } & \multirow{2}{*}{ KMO } & \multirow{2}{*}{ MSA } & \multirow{2}{*}{$\begin{array}{c}\text { Communalit } \\
\text { ies }\end{array}$} & \multirow{2}{*}{$\begin{array}{c}\text { Component } \\
\text { Matrix }\end{array}$} & \multirow{2}{*}{$\begin{array}{l}\text { Kriteria } \\
\text { Validitas }\end{array}$} \\
\hline Latent & Indikator & & & & & \\
\hline \multirow{27}{*}{$\begin{array}{l}\text { Kepuasan } \\
\text { Wisatawan }\end{array}$} & P1 & \multirow{27}{*}{0,851} & 0,899 & 0,556 & 0,693 & Valid \\
\hline & P2 & & 0,846 & 0,618 & 0,545 & Valid \\
\hline & P3 & & 0,763 & 0,559 & 0,406 & Valid \\
\hline & P4 & & 0,873 & 0,698 & 0,551 & Valid \\
\hline & P5 & & 0,776 & 0,598 & 0,331 & Valid \\
\hline & P6 & & 0,814 & 0,662 & 0,507 & Valid \\
\hline & P7 & & 0,815 & 0,694 & 0,543 & Valid \\
\hline & P8 & & 0,869 & 0,651 & 0,709 & Valid \\
\hline & P9 & & 0,872 & 0,700 & 0,656 & Valid \\
\hline & P10 & & 0,889 & 0,602 & 0,548 & Valid \\
\hline & $\mathrm{P} 11$ & & 0,898 & 0,717 & 0,698 & Valid \\
\hline & P12 & & 0,863 & 0,613 & 0,503 & Valid \\
\hline & P13 & & 0,872 & 0,637 & 0,542 & Valid \\
\hline & P14 & & 0,810 & 0,715 & 0,567 & Valid \\
\hline & P15 & & 0,764 & 0,763 & 0,511 & Valid \\
\hline & P16 & & 0,892 & 0,754 & 0,645 & Valid \\
\hline & P17 & & 0,829 & 0,607 & 0,570 & Valid \\
\hline & P18 & & 0,798 & 0,676 & 0,427 & Valid \\
\hline & P19 & & 0,869 & 0,716 & 0,612 & Valid \\
\hline & P20 & & 0,804 & 0,661 & 0,451 & Valid \\
\hline & $P 21$ & & 0,889 & 0,732 & 0,694 & Valid \\
\hline & P22 & & 0,842 & 0,688 & 0,649 & Valid \\
\hline & P23 & & 0,783 & 0,626 & 0,576 & Valid \\
\hline & P24 & & 0,881 & 0,426 & 0,524 & Valid \\
\hline & P25 & & 0,917 & 0,656 & 0,720 & Valid \\
\hline & P26 & & 0,894 & 0,698 & 0,560 & Valid \\
\hline & P27 & & 0,841 & 0,744 & 0,561 & Valid \\
\hline
\end{tabular}




\begin{tabular}{|c|c|c|c|c|c|}
\hline \multirow{4}{*}{ P28 } & & 0,839 & 0,710 & 0,637 & Valid \\
\cline { 1 - 4 } & P29 & 0,889 & 0,732 & 0,694 & Valid \\
\hline & P30 & 0,842 & 0,688 & 0,649 & Valid \\
\hline & P31 & 0,783 & 0,626 & 0,576 & Valid \\
\hline & P32 & 0,881 & 0,426 & 0,524 & Valid \\
\hline & P33 & 0,917 & 0,656 & 0,720 & Valid \\
\hline & P34 & 0,894 & 0,698 & 0,560 & Valid \\
\hline & P35 & 0,841 & 0,744 & 0,561 & Valid \\
\hline & P36 & 0,839 & 0,710 & 0,637 & Valid \\
\hline
\end{tabular}

Sumber: Output SPSS 20

Tabel 3 Hasil Uji Validitas Loyalitas Wisatawan

\begin{tabular}{|c|c|c|c|c|c|c|}
\hline \multicolumn{2}{|l|}{ Variabel } & \multirow{2}{*}{$\mathrm{KMO}$} & \multirow{2}{*}{ MSA } & \multirow{2}{*}{$\begin{array}{l}\text { Commun } \\
\text { alities }\end{array}$} & \multirow{2}{*}{$\begin{array}{c}\text { Compone } \\
\text { nt } \\
\text { Matrix }\end{array}$} & \multirow{2}{*}{$\begin{array}{l}\text { Kriteria } \\
\text { Validitas }\end{array}$} \\
\hline Latent & Indikator & & & & & \\
\hline \multirow{10}{*}{$\begin{array}{l}\text { Loyalitas } \\
\text { Kons. }\end{array}$} & P37 & \multirow{10}{*}{0,905} & 0,901 & 0,576 & 0,759 & Valid \\
\hline & P38 & & 0,895 & 0,535 & 0,732 & Valid \\
\hline & P39 & & 0,880 & 0,579 & 0,761 & Valid \\
\hline & $\mathrm{P} 40$ & & 0,917 & 0,592 & 0,770 & Valid \\
\hline & P41 & & 0,941 & 0,522 & 0,723 & Valid \\
\hline & P42 & & 0,921 & 0,593 & 0,770 & Valid \\
\hline & P43 & & 0,849 & 0,472 & 0,687 & Valid \\
\hline & P44 & & 0,910 & 0,515 & 0,718 & Valid \\
\hline & P45 & & 0,910 & 0,493 & 0,702 & Valid \\
\hline & P46 & & 0,931 & 0,562 & 0,750 & Valid \\
\hline
\end{tabular}

Sumber: Output SPPS 20

Berdasarkan Tabel diatas, dapat diketahui bahwa semua indikator penelitian (46 indikator) memenuhi kriteria uji validitas sehingga dapat dianalisis lebih lanjut. Selanjutnya dilakukan pengujian realibilitas menggunakan cronbach's coefficient alpha dengan bantuan software SPSS. Koefisien alpha cronbach bernilai antara 0 sampai dengan 1 dan batasan nilai alpha cronbach yang umum digunakan adalah lebih besar sama dengan $0,7(\geq 0,7)$. Nilai alpha cronbach kurang dari $0,6(<0,6)$ menindikasikan bahwa realibilitas dari instrumen yang digunakan kurang memenuhi (Hair et al, 2006). 


\section{b. Uji Reliabilitas}

\section{Tabel 4 Uji Reliabilitas}

\begin{tabular}{|c|c|c|}
\hline Variabel Latent & $\begin{array}{c}\text { Koefisien reliabilitas } \\
\text { Cronbach's Alpha }\end{array}$ & Kriteria Uji \\
\hline $\begin{array}{c}\text { Kepuasaan } \\
\text { Wisatawan }\end{array}$ & 0,920 & Reliabel \\
\hline $\begin{array}{c}\text { Loyalitas } \\
\text { Wisatawan }\end{array}$ & 0,905 & Reliabel \\
\hline
\end{tabular}

Sumber: Output SPSS 20

\section{Uji Goodness -of -fit Indices}

Tabel 5 Evaluasi Kriteria Goodness-of-fit Indices

\begin{tabular}{|l|c|c|c|}
\hline \multicolumn{1}{|c|}{ Kreteria } & Hasil Model ini & Nilai Kritis & $\begin{array}{c}\text { Evaluasi } \\
\text { Model }\end{array}$ \\
\hline $\begin{array}{l}\text { Chi-Square } X^{2} \\
\text { CMIN }\end{array}$ & 1.210 & $\begin{array}{l}\text { Besar, } X^{2} \\
\text { dengan } \mathrm{df}=4 \\
\text { adalah } 1.20\end{array}$ & \\
\hline Probability (P) & 0.876 & $\geq 0.05$ & Baik \\
\hline$X^{2}$ Relatif (CMIN/DF) & 0.303 & $\leq 2.0$ & Baik \\
\hline GFI & 0.9997 & $\geq 0.90$ & Baik \\
\hline AGFI & 0.988 & $\geq 0.90$ & Baik \\
\hline TLI & 1.020 & $\geq 0.95$ & Baik \\
\hline CFI & 1.000 & $\geq 0.95$ & Baik \\
\hline RMSEA & 0.000 & $\leq 0.08$ & Baik \\
\hline Sumber : Pengolahan & Ams & &
\end{tabular}

Sumber : Pengolahan data Amos SPSS

Confirmatory Factor Analysis pada measurement model dalam penelitian ini menunjukan model yang baik, dimana nilai GFI lebih tinggi dari tingkat yang disarankan 0.9; begitu juga dengan kriteria yang lain

\section{Hasil Regression Weight}

Tabel 6 Regression Weight (Loading Factor) Measurement Model Kepuasaan Terhadap Loyalitas Wisatawan

\begin{tabular}{|l|c|c|c|c|c|}
\hline \multicolumn{1}{|c|}{ Regression Weight } & $\begin{array}{c}\text { Estimat } \\
\mathrm{e}\end{array}$ & $\begin{array}{c}\text { Standardis } \\
\text { ed } \\
\text { Estimate }\end{array}$ & $\begin{array}{c}\text { Standa } \\
\text { rd } \\
\text { Error }\end{array}$ & C.R & $\mathrm{P}$ \\
\hline $\begin{array}{l}\text { Loyalitas wisatawan<--- } \\
\text { kepuasaan wisatawan }\end{array}$ & .897 & .783 & .108 & 8.302 & $* \star *$ \\
\hline $\begin{array}{l}\text { Ekspektasi <--- } \\
\text { kepuasaan wisatawan }\end{array}$ & 1.000 & .817 & & & \\
\hline
\end{tabular}




\begin{tabular}{|l|c|c|c|c|c|}
\hline $\begin{array}{l}\text { Kepuasan atribut <--- } \\
\text { kepuasaan wisatawan }\end{array}$ & 1.055 & .844 & .102 & $\begin{array}{c}10.30 \\
5\end{array}$ & $* * *$ \\
\hline $\begin{array}{l}\text { Tujuan Umum <--- } \\
\text { kepuasaan wisatawan }\end{array}$ & .812 & .648 & .102 & 7.926 & $* * *$ \\
\hline $\begin{array}{l}\text { Niat kembali <--- } \\
\text { loyalitas wisatawan }\end{array}$ & 1.000 & .865 & & & \\
\hline $\begin{array}{l}\text { Rekomendasi <--- } \\
\text { loyalitas wisatawan }\end{array}$ & .917 & .843 & .090 & $\begin{array}{c}10.14 \\
0\end{array}$ & $* * *$ \\
\hline
\end{tabular}

Sumber : Pengolahan data Amos SPSS

Tabel diatas menunjukan hasil regresi yang diperoleh melalui hasil perhitungan dengan menggunakan Amos SPSS, dari hasil regersi diperoleh hampir semua pengaruh memiliki nilai $P$ lebih kecil $\leq 0,05$ dan Critical Ratio $\geq 1,96$ artinya mendukung hipotesis :

1. Hipotesis pertama diterima kepuasan wisatawan mempunyai pengaruh positip terhadap Loyalitas wisatawan .

2. Hipotesis kedua diterima kepuasan tujuan umum, kepuasan atribut tujuan dan harapan terpenuhi mempunyai pengaruh positip terhadap kepuasaan wisatawan.

3. Hipotesis ketiga diterima niat untuk kembali dan kemauan untuk merekomendasikan mempunyai pengaruh yang positip terhadap loyalitas.

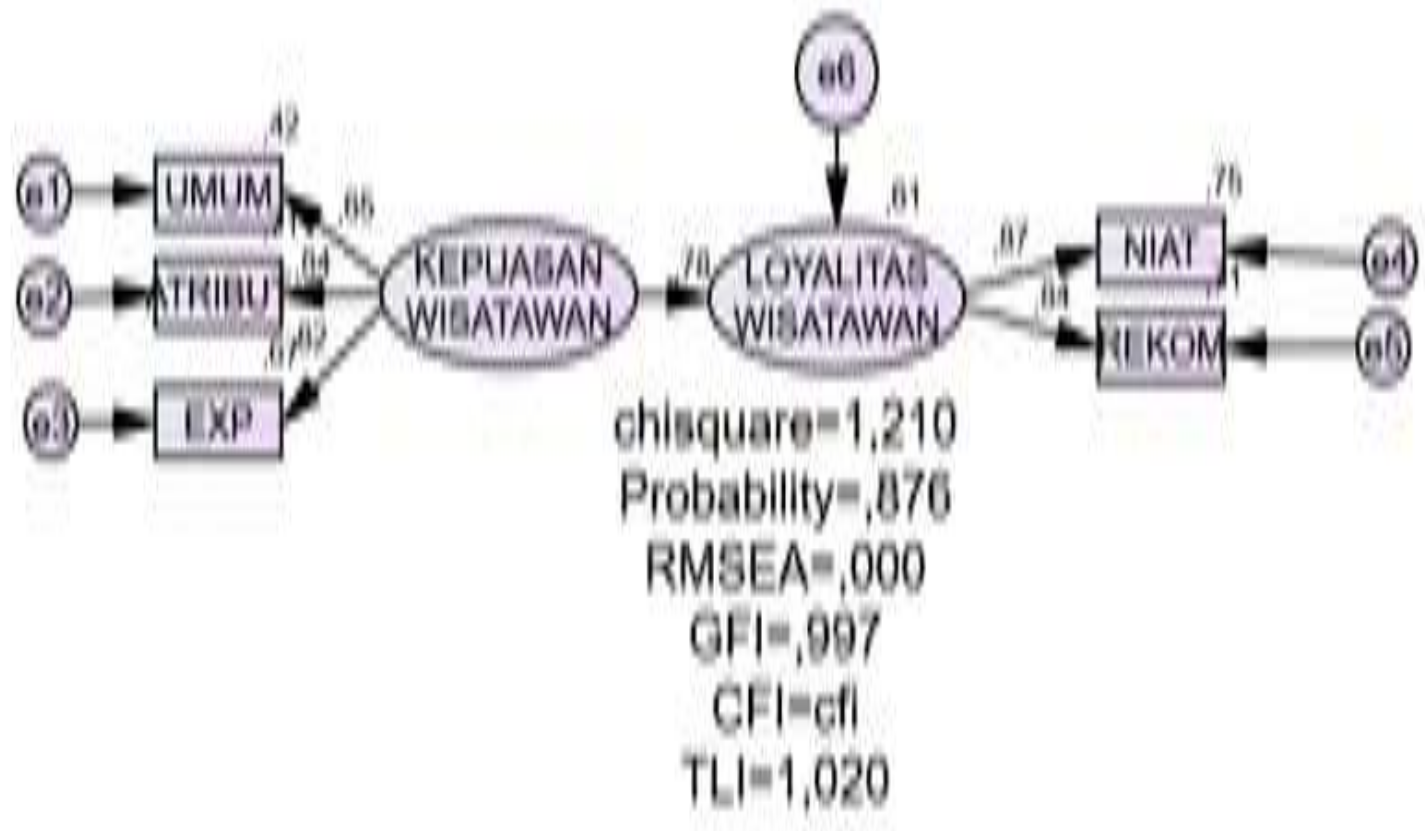

Gambar 2 Hasil Pengolahan Data Amos SPSS 23 


\section{E. Kesimpulan dan Saran}

\section{Kesimpulan}

1. Kepuasan wisatawan berpengaruh positif terhadap Loyalitas wisatawan Lokal pada objek wisata kepulauan seribu Jakarta, dimana nilai t value sebasar 8,302 $\geq 1,96$

2. Kepuasaan tujuan umum (general destination satisfaction)", kepuasan atribut tujuan (attribute satisfaction)" dan kepuasaan harapan (met expectation) berpengaruh positif terhadap kepuasan wisatawan Lokal pada objek wisata Kepulauan seribu Jakarta, dimana nilai t value sebesar $10,305 \geq 1,96$

3. Niat untuk kembali (intention to return) dan kemauan untuk merekomendasikan (willingness to recommended) berpengaruh positif terhadap loyalitas, dimana nilai $\mathrm{t}$ value sebesar $10.140 \geq 1,96$

\section{Saran}

1. Disarankan kepada pengelola objek wisata Kepulauan Seribu Jakarta agar dapat menjaga keindahan pantai dan alam bawa laut, kesegaran udara karena hal ini yang membuat wisatawan merasa senang untuk berkunjung

2. Disarankan juga untuk menigkatkan pelayanan, menambah fasilitas transportasi, toilet umum yang bersih, lebih banyak lagi tong sampah, penginapan yang nyaman dan murah dengan lahan parikir yang luas, layanan penjulan tiket yang cepat dan ramah, food court yang bersih dan harga standar tidak menguras kantong wisatawan, agar dapat meningkatkan kepuasan wisatawan.

3. Menigkatkan keamanan, menjaga hubungan baik dengan wisatawan agar wisatawan Loyal sehingga berniat utuk kembali berkunjung dan merekomnedasikan kepada wisatawan lain.

\section{Daftar Pustaka}

Alexandros A., Shabbar, J. (2005). Stated preferences for two Cretan heritage attractions. Annals of Tourism Research, 32(4), 985-1005.

Baker, D A., \& Crompton, J. L. (2000). Quality, satisfaction and behavioural intentions. Annals of Tourism Research, 27(3), 785-804.

Bramwell, B. (1998). User satisfaction and product development in urban tourism. Tourism Management, 19(1), 35-47.

Bauer, H., Mark, G., \& Leach, M. (2002). Building customer relations over the internet. Industrial Marketing Management, 31(2), 155-163.

Beerli,A.,\&Martín,J.D.(2004).Tourists'characteristicsandtheperceivedimage of tourist destinations: a quantitative analysis - a case study of Lanzarote, Spain. Tourism Management, 25(5), 623-636.

Bigné, J. E., Sánchez, M. I., \& Sánchez, J. (2001). Tourism image, evaluation variables and afterpurchase behaviour: inter-relationship. Tourism Management, 22(6), 607-616.

Bigné, J. E., Andreu, L., \& Gnoth, J. (2005). The theme park experience: an analysis of pleasure, arousal and satisfaction. Tourism Management, 26(6), 833-844.

Bigné, J.E., \& Andreu, L. (2004). Emotions in segmentation: an empirical study. Annals of Tourism Research, 31(3), 682-696. 
Bitner, M. J. (1990). Evaluating service encounter: the effects of physical surroundings and employee responses. Journal of Marketing, 54, 69-82.

Brodie, R. J., Coviello, N. E., Brookes, R. W., \& Victoria, L. (1997). Towards a paradigm shift in marketing: an examination of current marketing practices. Journal of Marketing Management, 13(5), 383-406.Cai, L.A., Wu, B.

Bowen, D. (2001). Antecedents of consumer satisfaction and dis-satisfaction (CS/D) on Long-Haul inclusive tours: a reality check on theoretical considerations. Tourism Management, 22, 49-61.

Cai, L.A., Wu, B. \& Bai, B. (2003). Destination image and loyalty, Cognizant Communication Corporation, 7, 153-162.

Chen,J.,\&Gursoy,D. (2001).Aninvestigationoftourists'destinationloyalty and preferences,

Chon, K, (1989). Understanding recreational travellers' motivation, attitude and satisfaction. The Tourist Review, 44(1), 3-7.

Dick, A. S., \& Basu, K. (1994). Customer loyalty: toward an integrated conceptual framework. Journal of the Academy of Marketing Science, 22(2), 99-113.

Flavian, C., Martinez, E., \& Polo, Y. (2001). Loyalty to grocery stores in the Spanish market of the 1990s. Journal of Retailing and Consumer Services, 8, 85-93.

Font, A. R. (2000). Mass tourism and the demand for protected natural areas: a trave cost approach. Journal of Environmental Economics and Management, 39(1), 97-116.

Fornell C. (1992). A National Customer Satisfaction Barometer: The Swedish Experience. Journal of Marketing, 56(1), 6-21.

Francken, D. A., \& Van Raaji, W. F. (1981). Satisfaction with leisure time activities. Journal of Leisure Research, 13(4), 337-352.

Gallarza, M.G., \& Saura, I. $\quad$ G. (2006). Value dimensions, perceived value, satisfaction and loyalty: an investigation of university students' travel behaviour. Tourism Management, 27 (3), 437-452.

Hallowell R. (1996). The Relationship of Customer Satisfaction, Customer Loyalty, Profitability: An Empirical Study. International Journal of Service Industry Management, 7(4), 27-42.

Hair, J., Anderson, R., Tathan, R., \& Black, W. (1995). Multivariate data analysis with readings $\left(4^{\text {th }}\right.$ ed. $)$. New Jersey: Prentice-Hall.

Hair, et.al,. (2006). Multivariate Data Analysis $6^{\text {th }}$ Edition. Pearson International Edition. New Jersey.

Kotler, P. (1994). Marketing Management: Analysis, Planning, Implementation and Control (8thed.). Englewood Cliffs NJ: Prentice-Hall International.

Kozak, M., Rimmington, M. (2000). Tourism satisfaction with Mallorca, Spain, as an offseason holiday destination. Journal of Travel Research, 38(3), 260-269. Kozak, M. (2001). Repeaters' behaviour at two distinct destinations. Annals of Tourism Research, 28, 784-807.

La Barbara, P.A., \& Mazursky, D. (1983). A Longitudinal Assessment of Consumer Satisfaction/Dissatisfaction: The Dynamic Aspect of the Cognitive Process. Journal of MarketingResearch, 20, 393-404.

Mazursky, D. (1989). Past experience and future tourism decisions. Annals of Tourism Research, 16, 333-344.

Malhotra, Naresh K. (2007). Marketing Research: an Applied Orientation. 5th edition.

Mai, L.W. \& Ness, M. R. (2006). A Structural Equation Model of Customer Satisfaction and Future Purchase of Mail-Order Speciality Food. International Journal of Business Science and Applied Management, 1(1), 1-13. 
Malhotra, Naresh K. (2007). Marketing Research: an Applied Orientation. $5^{\text {th }}$ edition.

Pearson Education. New Jersey

Mittal, V. M., \& Kamakura, W. (2001). Satisfaction, repurchase intent and repurchase behaviour: Investigating the moderating effect of customer characteristics, Journal of Marketing Research, 131-142.

Niininen O., Szivas, E. \& Riley, M. (2004). Destination loyalty and repeat behaviour: An application of optimum stimulation measurement, International Journal of Tourism Research, 6, 439-44. International Journal of Contemporary hospitality Management, 13, 79-86.

Noe, F. P., \& Uysal, M. (1997). Evaluation of outdoor recreational settings. problem of measuring user satisfaction. Journal of Retailing and Consumer Services, 4(4), 223-230.

Oh, h. (1999). Service quality, customer satisfaction, and customer value: a holistic perspective. International Journal of Hospitality Management, 18, 67-82

Oliver, R. L. (1980). A cognitive model of the antecedents and consequences of satisfaction decisions. Journal of Marketing Research, 17, 46-49.

Oliver, R. L. (1999). Whence consumer loyalty? Journal of Marketing, 63, 33-44. Oppermann, M. (2000). Tourism destination loyalty. Journal of Travel Research, 39, 78-84.

Petrick, J. F. (2004). Are loyal visitors desired visitors? Tourism Management, 25(4), 463-470. Pine, B. J., Peppers, D., \& Rogers, M. (1995). Do you want to keep your customers forever? Harvard Business Review, March-April, 103-14.

Ross, R. L., \& Iso-Ahola, S. E. (1991). Sightseeing tourists' motivation and satisfaction. Annals of Tourism Research, 18(2), 226-237.

Sangpikul, Aswin (2018). The effects of travel experience dimensions on tourist satisfaction and destination loyalty: the case of an island destination. International Journal of Culture, Tourism, and Hospitality Research.

Schofield, P. (2000). Evaluating Castlefield urban heritage park from the consumer perspective: destination attribute importance, visitor perception, and satisfaction. Tourism Analysis, 5(2-4), 183-189.

Sholihin, Mahfud \& Ratmono, Dwi. (2013). Analisis SEM-PLS dengan WarpPLS 3.0 untuk hubungan nonlinier dalam penelitian sosial dan bisnis. Yogyakarta: Andi

Tourism Management, 19(1), 35-47

Supriyadi, "Perangkat Lunak Statistik SPSS + Amos", Jakarta, 2014.

Sugiono (2013). Cara Mudah Menyusun Skripsi, Tesis dan Disertasi (STD), Alfabeta, Bandung

Turnbull, P., \& Wilson, D. T. (1989). Developing and protecting profitable customer relationships. Industrial Marketing Management, 18, 233-238.

Um, S., Chon, K., \& Ro, Y. (2006). Antecedents of revisit intention. Annals of Tourism Research, 33 (4), 1141-1158.

Valle, Silva, Mendes, Guerreiro. (2006). Tourist satisfaction and destination loyalty intention: A structural and categorical analysis. Int. Journal of Business Science and Applied Management, Volume 1, Issue 1.

Weaver, P.A., McCleary, K.W., Lepisto, L., \& Damonte, L.T. (1994). The relationship of destination selection attributes to psychological, behavioural and demographic variables. Journal of Hospitality and Leisure Marketing, 2(2), 93-109

Woodside, A., \& Lysonski, S. (1989). A General model of traveller destination choice. Journal of Travel Research, 27(4), 8-14. 
Yoon, Y., \& Uysal, M. (2005). An examination of the effects of motivation and satisfaction on destination loyalty: a structural model. Tourism Management, 26(1), 45-56.

Zimmer, Z., Brayley, R. E., \& Searle, M. S. (1995). Whether to go and where to go: identification of important influences on seniors' decisions to travel. Journal of Travel Research, 33(3), 3-10. 